\title{
Cinacalcet corrects hypercalcemia in mice with an inactivating $\mathrm{G} \alpha_{11}$ mutation
}

\author{
Sarah A. Howles, ${ }^{1}$ Fadil M. Hannan, ${ }^{1,2}$ Caroline M. Gorvin, ${ }^{1}$ Sian E. Piret, ${ }^{1}$ Anju Paudyal, ${ }^{3}$ \\ Michelle Stewart, ${ }^{3}$ Tertius A. Hough, ${ }^{3}$ M. Andrew Nesbit,, ${ }^{1,4}$ Sara Wells, ${ }^{3}$ Stephen D.M. Brown, ${ }^{3}$ \\ Roger D. Cox, ${ }^{3}$ and Rajesh V. Thakker ${ }^{1}$ \\ 'Academic Endocrine Unit, Radcliffe Department of Medicine, University of Oxford, Oxford, United Kingdom. \\ 2Department of Musculoskeletal Biology, Institute of Ageing and Chronic Disease, University of Liverpool, Liverpool, \\ United Kingdom. ${ }^{3}$ Mammalian Genetics Unit and Mary Lyon Centre, Medical Research Council (MRC) Harwell Institute, \\ Harwell Science and Innovation Campus, United Kingdom. ${ }^{4}$ Biomedical Sciences Research Institute, Ulster University, \\ Coleraine, United Kingdom.
}

Loss-of-function mutations of $C N A 11$, which encodes G-protein subunit $\alpha_{11}\left(G \alpha_{11}\right)$, a signaling partner for the calcium-sensing receptor (CaSR), result in familial hypocalciuric hypercalcemia type $\mathbf{2}$ (FHH2). $\mathrm{FHH} 2$ is characterized by hypercalcemia, inappropriately normal or raised parathyroid hormone (PTH) concentrations, and normal or low urinary calcium excretion. A mouse model for FHH2 that would facilitate investigations of the in vivo role of $\mathrm{G} \alpha_{11}$ and the evaluation of calcimimetic drugs, which are CaSR allosteric activators, is not available. We therefore screened DNA from $>10,000$ mice treated with the chemical mutagen $\mathrm{N}$-ethyl- $\mathrm{N}$-nitrosourea (ENU) for CNA11 mutations and identified a $\mathrm{G} \alpha_{11}$ variant, Asp195Gly (D195G), which downregulated CaSR-mediated intracellular calcium signaling in vitro, consistent with it being a loss-of-function mutation. Treatment with the calcimimetic cinacalcet rectified these signaling responses. In vivo studies showed mutant heterozygous (Gna11+/195C) and homozygous (Gna1195C/195C) mice to be hypercalcemic with normal or increased plasma PTH concentrations and normal urinary calcium excretion. Cinacalcet $(30 \mathrm{mg} / \mathrm{kg}$ orally) significantly reduced plasma albumin-adjusted calcium and PTH concentrations in Gna11+/195C and Gna1195C/195C mice. Thus, our studies have established a mouse model with a germline loss-offunction $\mathrm{C} \alpha_{11}$ mutation that is representative for $\mathrm{FHH} 2$ in humans and demonstrated that cinacalcet

Authorship note: SAH, FMH, and CMG contributed equally to this work.

Conflict of interest: FMH and RVT have received grant funding from NPS/Shire Pharmaceuticals and ClaxoSmithKline for studies involving the use of calciumsensing receptor (CaSR) allosteric inhibitors. RVT has also received grants from Novartis Pharma AG and the Marshall Smith Syndrome Foundation for unrelated studies. SDMB declares ownership of shares in Pulmagen Therapeutics.

License: This work is licensed unde the Creative Commons Attribution 4.0 International License. To view a copy of this license, visit http:// creativecommons.org/licenses/ by/4.0/.

Submitted: July 27, 2017 Accepted: September 19, 2017 Published: October १९, 2017

\section{Reference information:} JCI Insight. 2017;2(20):e96540. https://doi.org/10.1172/jci. insight. 96540. can correct the associated abnormalities of plasma calcium and PTH.

\section{Introduction}

Familial hypocalciuric hypercalcemia $(\mathrm{FHH})$ is an autosomal dominant disorder of extracellular calcium $\left(\mathrm{Ca}^{2+}{ }_{\mathrm{o}}\right)$ homeostasis characterized by lifelong elevations in serum calcium concentrations in association with normal or mildly elevated serum parathyroid hormone (PTH) concentrations and normal or low fractional excretion of calcium (1-4). FHH is caused by a reduction in the sensitivity of the $\mathrm{Ca}^{2+}{ }_{0}$-sensing receptor (CaSR) signaling pathway to alterations in the prevailing $\mathrm{Ca}^{2+}{ }_{\mathrm{o}}$ concentration $\left(\left[\mathrm{Ca}^{2+}\right]_{0}\right)(1-4)$. The CaSR is a widely expressed family C GPCR that regulates PTH secretion and urinary calcium excretion by transducing elevations in $\left[\mathrm{Ca}^{2+}\right]_{0}$ into multiple intracellular signaling cascades in the parathyroid glands and kidneys, respectively $(5,6)$. In the parathyroid glands, the CaSR has been shown to couple to the $\mathrm{G}_{\mathrm{q} / 11}$ protein family (7), which activates phospholipase C (PLC), thereby increasing intracellular calcium $\left(\mathrm{Ca}^{2+}\right)$ and MAPK signaling responses $(8,9)$, which in turn leads to decreased parathyroid PTH secretion.

$\mathrm{FHH}$ is a genetically heterogeneous disorder with 3 recognized forms referred to as FHH types 1-3 (FHH1-3) (1). FHH1 (OMIM 145980) is caused by heterozygous loss-of-function mutations of the CaSR, which is encoded by the CASR gene on chromosome 3q21.1 (1). FHH2 (OMIM 145981) is due to heterozygous loss-of-function mutations of G-protein subunit $\alpha_{11}\left(\mathrm{G} \alpha_{11}\right)$, which is encoded by the GNA11 gene on chromosome $19 \mathrm{p} 13.3$, and to date, $3 \mathrm{FHH} 2$-associated mutations have been reported, comprising 2 missense mutations, Thr54Met and Leu135Gln, and an in-frame isoleucine deletion at codon 200 (Ile200del) $(3,10)$. FHH3 (OMIM 600740) is caused by heterozygous loss-of-function mutations of the adaptor protein-2 $\sigma$ subunit (AP2 $\sigma$ ), encoded by the $A P 2 S 1$ gene on chromosome $19 \mathrm{q} 13.3$, which is involved in the clathrin-mediated endocytosis of cell-surface proteins such as the CaSR $(4,11)$. 
A mouse model for FHH1 has previously been generated by targeted germline disruption of the Casr gene, and heterozygous ( $\left.\mathrm{Casr}^{+/}\right)$mice were shown to have a phenotype resembling that of FHH1 patients with elevated serum concentrations of calcium and PTH, and low urinary calcium excretion (12). In addition, homozygous ( $\mathrm{Casr}^{\circ-}$ ) mice had features of neonatal severe hyperparathyroidism (NSHPT), which is caused by biallelic inactivating CaSR mutations (1), and exhibited growth retardation and died within the first 30 days of life (12). An in vivo model is not available for $\mathrm{FHH} 2$, although mice with parathyroid-specific combined ablations of both the Gnall and Gnaq (encoding $G \alpha_{\mathrm{q}}$ ) genes have previously been reported to develop marked hypercalcemia and hyperparathyroidism (7). We therefore sought to establish a mouse model for FHH2 to define the in vivo role of $\mathrm{Ga}_{11}$ in $\mathrm{Ca}^{2+}{ }_{\mathrm{o}}$ homeostasis and to undertake a more detailed characterization of the phenotype of this disorder, as limited information is available from the few FHH2 patients reported, to date $(3,10)$. In addition, a mouse model for FHH2 would facilitate evaluation of therapeutic drugs such as CaSR allosteric activators, also known as calcimimetics (13). To establish a mouse model for FHH2, due to a germline lossof-function GNA11 point mutation $(3,10)$, we screened a DNA archive of $>10,000$ samples from male mice that had mutations induced by treating them with $N$-ethyl- $N$-nitrosourea (ENU), a chemical mutagen. ENU is an alkylating agent that introduces point mutations via transfer of an alkyl group from ENU to a DNA base, thus leading to mispairing and bp substitution during subsequent DNA replication $(14,15)$. ENU mutagenesis programs utilize two complementary approaches that are phenotype-driven and genotype-driven screens. In phenotype-driven screens, offspring of mutagenized mice are assessed for abnormalities in a hypothesis-generating strategy, which may elucidate new genes, pathways, and mechanisms for disease phenotypes $(14,15)$. Genotype-driven screens in which mutations in the gene of interest are sought are hypothesis driven and are feasible by available parallel archives of tissue-DNA and sperm samples from mutagenized male mice (14, 15). The archived tissue-DNA samples from the mutagenized male mice are used to search for the mutations in the gene of interest, and once these mutations are found, a sperm sample from the male mouse with the mutation is used for in vitro fertilization (IVF) of normal female mice to establish progeny with the mutation $(14,15)$. The probability of finding 3 or more variant alleles in an archive of tissue-DNA samples from $>5,000$ ENU-mutagenized mice is $>90 \%$ (14). We sought for ENU-induced Gna11 variants in tissue-DNA samples from $>10,000$ male mice treated with ENU, with the aim of establishing a mouse model for FHH2.

\section{Results}

Identification and analysis of 5 Gna11 variants in ENU-mutagenized mice. An analysis using melting curve analysis (16) of tissue-DNA samples from $>10,000$ ENU-mutagenized male mice of the 7 exons and 12 intron-exon boundaries of the Gna11 gene revealed the presence of 5 Gnal1 variants, comprising c.379C $>$ T, c.395T $>$ A, c. $440 \mathrm{G}>\mathrm{A}$, c. $584 \mathrm{~A}>\mathrm{G}$, and c.806T $>$ C (numbering starts from ATG; Supplemental Table 1; supplemental material available online with this article; https://doi.org/10.1172/jci.insight.96540DS1; numbering in Supplemental Table 1 starts from 5'UTR.). These 5 Gnall variants predicted the occurrence of 4 missense variants (Ile132Asn, Arg147His, Asp195Gly, and Val269Ala) and 1 nonsense variant (Gln127Stop) (Figure 1A and Supplemental Figure 1). Bioinformatic analysis predicted all the $G \alpha_{11}$ variants to be damaging and likely disease-causing (Supplemental Table 1). FHH2 has been reported to be caused by either an in-frame deletion or missense substitutions affecting $\mathrm{G \alpha}_{11}(3,10)$, and we therefore further characterized only the 4 missense $\mathrm{G} \alpha_{11}$ variants identified in ENU-mutagenized mice. All of these 4 missense variants affected evolutionary-conserved residues (Figure 1B, Supplemental Table 1, and Supplemental Figure 1), and 2 variants (Asp195Gly and Val269Ala) were located in the $\mathrm{G} \alpha_{11}$ GTPase domain, which mediates GPCR binding, guanosine triphosphate (GTP) hydrolysis, and effector coupling. The other 2 variants (Ile132Asn and Arg147His) were located in the $\mathrm{G} \alpha_{11}$ helical domain, which stabilizes guanine nucleotide binding (Figure 1A and Supplemental Figure 1) (17). Three-dimensional (3-D) modeling using the reported crystal structure of the related $G \alpha_{q}$ protein (18) predicted the Asp195Gly variant to disrupt polar contacts within the $\mathrm{G} \alpha_{11}$ GTPase domain (Figure 1, C and D), whereas the other missense variants were not predicted to alter intramolecular interactions within the $\mathrm{G} \alpha_{11}$ protein (Supplemental Figure 1). We therefore selected the Asp195Gly (D195G) variant for functional characterization for the following 4 reasons. First, this variant is located within the switch regions of the $\mathrm{G}_{11}$ GTPase domain (Figure 1, B and C), which are critical for mediating G $\alpha$-subunit conformational changes upon GTP binding and also for coupling to downstream effector proteins such as PLC $(19,20)$. Second, the Asp195Gly variant is situated within a 13 amino acid region (residues 193-205), which links switches I and II (Figure 1, B and C) and is the location of a reported FHH2-causing $\mathrm{G} \alpha_{11}$ mutation (Ile200del) (3). Third, this 13-amino acid linker region also contains the tetrapeptide $\beta 2-\beta 3$ loop (residues 196-199), which mediates G-protein-GPCR inter- 
A
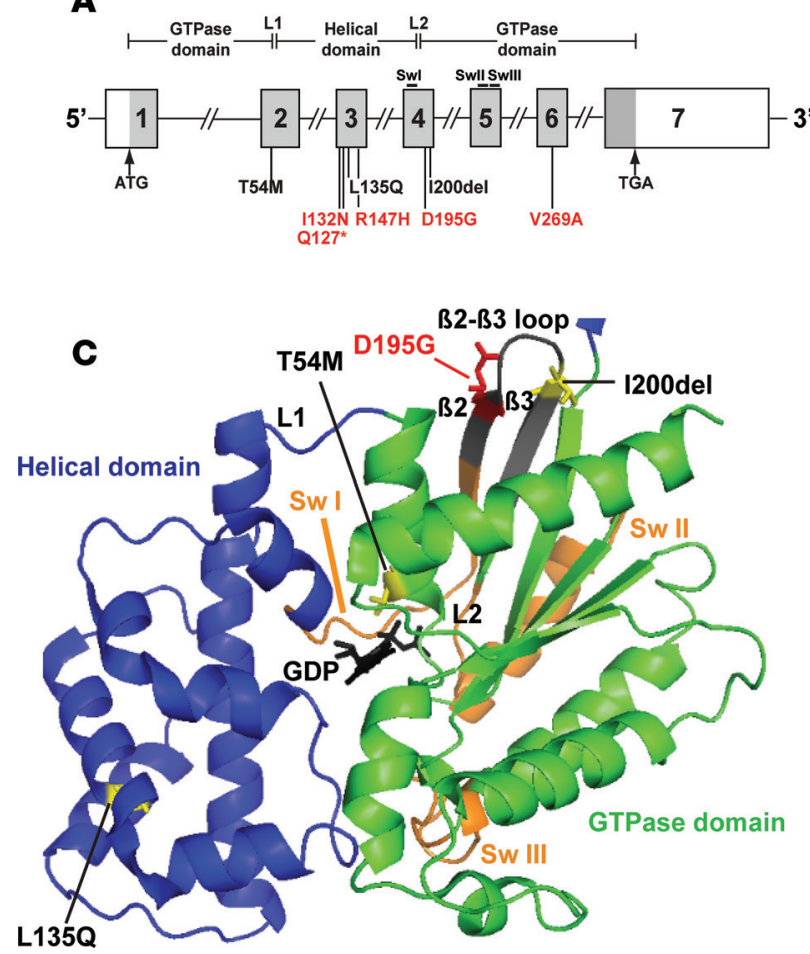

B

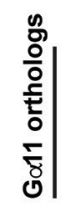

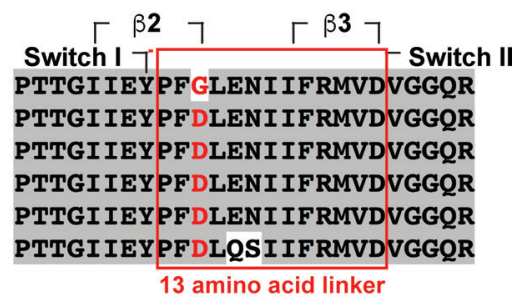

D

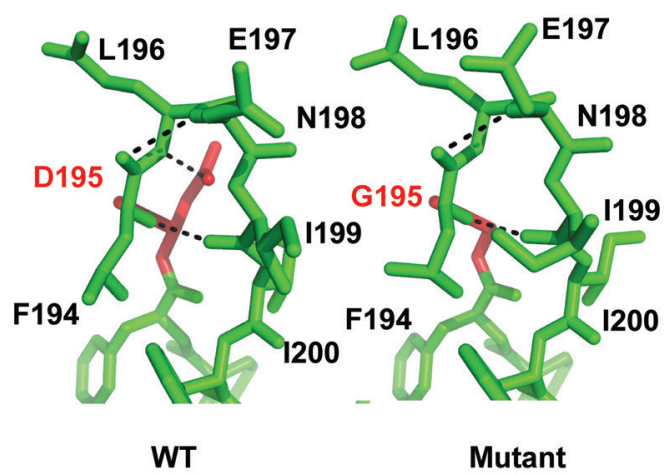

Figure 1. Structural characterization of the Asp195Gly $\mathbf{G} \alpha_{11}$ mutation. (A) Genomic organization of Gna11 showing the location of reported human familial hypocalciuric hypercalcemia type 2 ( $\mathrm{FHH} 2$ ) mutations (black) $(3,10)$ and Gna11 variants identified in $\mathrm{N}$-ethyl- $\mathrm{N}$-nitrosourea- mutagenized (ENU-mutagenized) mice (red). The G-protein subunit $\alpha_{11}\left(G \alpha_{11}\right)$ GTPase domain (encoded by exon 1, 5' portion of exon 2, 3'portion of exon 4 and exons 5-7) is connected to the helical domain (encoded by the 3'portion of exon 2, exon 3, and 5'portion of exon 4) by the linker 1 (L1) and 2 (L2) peptides. The GTPase domain contains 3 flexible regions, termed switch regions I-III (SwI-SwIII). The Asp195Gly mutation is located within the GTPase domain and between the switch I and II regions. (B) Multiple protein sequence alignment of $G \alpha_{11}$ residues comprising a 13-amino acid region that links the $\beta 2$ strand of the switch I region with the $\beta 3$ strand of the switch II region. Conserved residues are shown in gray. The WT (Asp, D) and mutant (m) (Cly, G) residues are shown in red. (C) Homology model of the GDP-bound $G \alpha_{11}$ protein. The $G \alpha$ helical (blue) and GTPase (green) domains and bound GDP nucleotide (black) are shown. Switch regions I-III are shown in orange. Previously reported residues mutated in $\mathrm{FHH} 2$ patients $(3,10)$ are shown in yellow. The mutated Asp195 residue (red) is located in a 13 -amino acid region (gray) and adjacent to the $\beta 2-\beta 3$ loop. (D) Close-up view the $\beta 2-\beta 3$ hairpin loop region of WT and mutant $G \alpha_{11}$ proteins showing the structural effects of the Asp195Gly mutant on hydrogen bonds (broken lines) within the hairpin loop. The Asp195Gly G $\alpha_{11}$ mutant is predicted to result in a loss of a polar contact (hydrogen bond) between the Asp195 side chain and the backbone of the Glu197 (E197) residue. The one-letter amino acid codes indicate the following: D, aspartic acid; E, glutamic acid; F, phenylalanine; G, glycine; I, isoleucine; L, leucine; M, methionine; N, asparagine; Q, glutamine; and T, threonine.

actions (21) (Figure 1C), and our reported mutagenesis studies have shown that disruption of the $G \alpha_{11} \beta 2-\beta 3$ loop impairs signaling in CaSR-expressing cells (3). Fourth, 3-D modeling of the Asp195Gly G $\alpha_{11}$ variant predicted that substitution of the WT Asp195 residue with the variant Gly195 residue would lead to a loss of a polar contact within the $\mathrm{G} \alpha_{11} \beta 2-\beta 3$ loop, which would likely disrupt this tetrapeptide loop (Figure 1D) and thereby impair GPCR binding and $\mathrm{G} \alpha_{11}$ activation $(3,19,20)$. These combined observations indicated that the Asp195Gly variant was highly likely to be a pathogenic mutation.

In vitro functional characterization of the Asp195Gly $G \alpha_{11}$ mutation. To investigate the effects of these predicted $\mathrm{G} \alpha_{11}$ structural changes due to the Asp195Gly mutation on CaSR-mediated signaling, human embryonic kidney 293 (HEK293) cells stably expressing the CaSR (HEK-CaSR) were transiently transfected with pBI-CMV2-GNA11-GFP constructs expressing either the WT (Asp195) or variant (Gly195) G $\alpha_{11}$ proteins, as reported (3). This bidirectional pBI-CMV2 vector allows for coexpression of $\mathrm{G} \alpha_{11}$ and GFP at equivalent levels (3). Expression of the CaSR, G $\alpha_{11}$, and GFP was confirmed by fluorescence microscopy and/or Western blot analyses (Figure 2, A and B). The expression of $\mathrm{G} \alpha_{11}$ was shown to be similar in cells transiently transfected with WT or mutant proteins and to be greater than that observed in untransfected cells (Figure 2B). Moreover, the expression of mutant $\mathrm{G} \alpha_{11}$ in cells that endogenously express WT $\mathrm{G} \alpha_{11}$ (Figure 2B) corresponded to the heterozygous situation reported in $\mathrm{FHH} 2$ patients $(3,10)$. The $\mathrm{Ca}^{2+}{ }_{\mathrm{i}}$ responses to alterations in $\left[\mathrm{Ca}^{2+}\right]_{0}$ of cells expressing the different GNA11 vectors were assessed using a multiwell assay that utilized the Fluo-4 $\mathrm{Ca}^{2+}$-binding dye, as reported (22). The $\mathrm{Ca}^{2+}{ }_{\mathrm{i}}$ responses were shown to increase in a dose-dependent manner following stimulation with increasing $\left[\mathrm{Ca}^{2+}\right]_{0}$ (Figure 2C). However, responses in mutant Gly195-expressing 
A
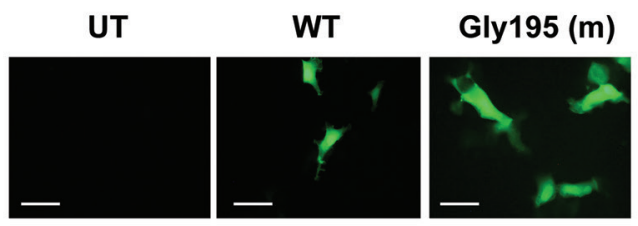

C

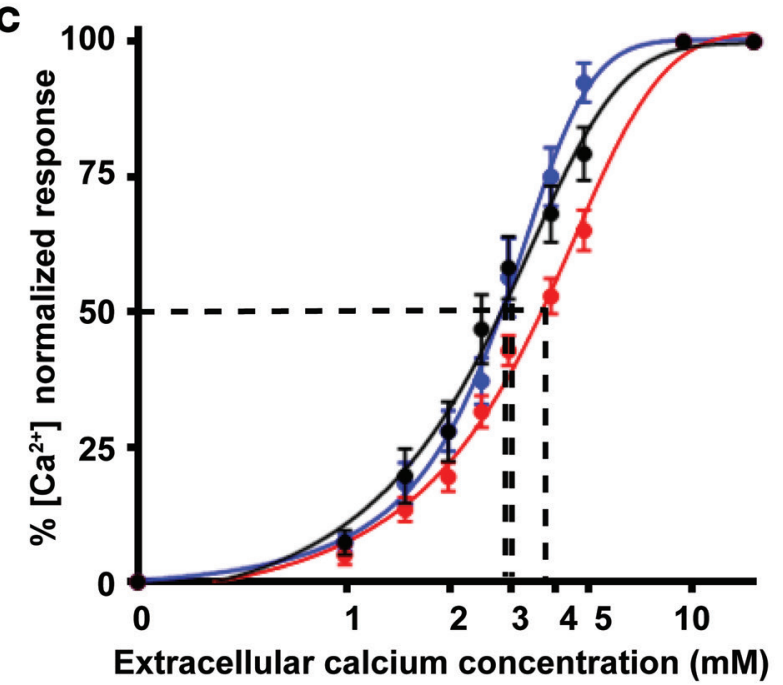

B

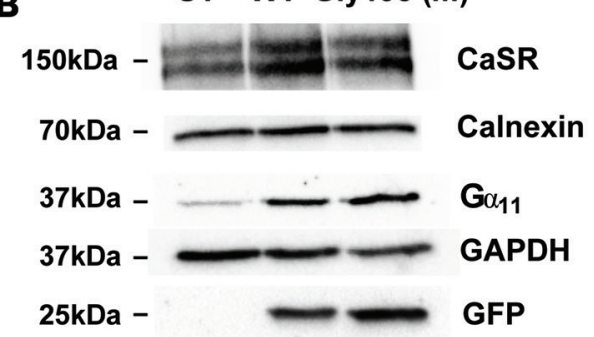

D

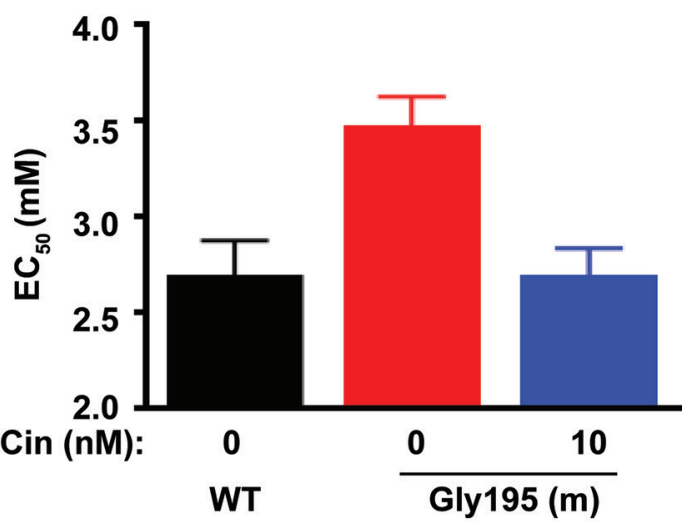

Figure 2. $\mathrm{Ca}^{2+}$, responses of the Gly195 $\mathbf{G} \alpha_{11}$ mutant and in vitro effect of cinacalcet treatment. (A) Fluorescence microscopy of untransfected (UT) HEK293 cells stably expressing calcium-sensing receptor (CaSR) (HEK-CaSR) and of HEK-CaSR cells transiently transfected with WT (Asp195) or mutant (m) Gly195 pBI-CMV2-GNA11-GFP constructs. GFP expression in these cells indicates successful transfection and expression by these constructs. Scale bar: $10 \mu \mathrm{m}$. (B) Western blot analysis of lysates from HEK-CaSR cells used for intracellular calcium $\left(\mathrm{Ca}^{2+}\right)$ experiments. Transient transfection with WT or mutant Gly195 G-protein subunit $\alpha_{11}\left(G \alpha_{11}\right)$ expression constructs resulted in overexpression of $G \alpha_{11}$ and GFP, whereas UT cells showed only endogenous $G \alpha_{11}$ protein expression. All cells expressed the CaSR. The calnexin and GAPDH proteins were used as loading controls. (C) $\mathrm{Ca}^{2+}$, responses to changes in [Ca ${ }^{2+}{ }_{0}$ of $\mathrm{HEK}-$ CaSR cells expressing WT or Gly195 $\mathrm{G} \alpha_{11}$ mutant proteins. The $\mathrm{Ca}^{2+}{ }_{\mathrm{i}}$ responses are expressed as a percentage of the maximum normalized responses and shown as the mean \pm SEM of 8 independent transfections. The Gly195 $\mathrm{G} \alpha_{11}$ mutant led to a rightward shift in the concentration-response curve (red line) compared with cells expressing WT $\mathrm{G} \alpha_{11}$ (black line). The addition of $10 \mathrm{nM}$ cinacalcet (Cin) normalized the shift of the mutant concentration-response curve (blue line). (D) Histogram showing the mean half-maximal concentration ( $\mathrm{EC}_{50}$ ) with 95\% Cl of WT cells (black), Cly195 mutant cells (red), and Gly195 mutant cells treated with $10 \mathrm{nM}$ cinacalcet (blue). Statistical analysis was performed using the F-test. ${ }^{* * *} P<0.0001$ compared with WT.

cells were significantly decreased compared with WT-expressing cells (Figure 2C). Thus, the mutant Gly195expressing cells showed a rightward shift in the concentration-response curve (Figure 2C), with a significantly increased mean half-maximal response $\left(\mathrm{EC}_{50}\right)$ of $3.39 \mathrm{mM}(95 \% \mathrm{CI}, 3.26-3.53 \mathrm{mM})$ compared with $2.70 \mathrm{mM}$ (95\% CI, 2.53-2.88 mM) for WT-expressing (Asp195) cells $(P<0.0001)$ (Figure 2, C and D). These results demonstrated that the $\mathrm{G} \alpha_{11}$ Asp195Gly mutation is a loss-of-function mutation, similar to mutations that lead to FHH2 $(3,10)$. We next investigated the ability of the CaSR allosteric activator, cinacalcet, to rectify this loss of function associated with the Asp195Gly G $\alpha_{11}$ mutation. Cinacalcet was added to Gly195 mutant cells at a $10 \mathrm{nM}$ concentration, as this dose has previously been reported to normalize the altered signaling responses associated with FHH2-causing $\mathrm{G} \alpha_{11}$ mutations in vitro (23). An assessment of $\mathrm{Ca}^{2+}{ }_{\mathrm{i}}$ responses showed 10 $\mathrm{nM}$ cinacalcet to induce a leftward shift of the concentration-response curve of cells expressing the Gly195 mutant $\mathrm{G} \alpha_{11}$ protein (Figure $2 \mathrm{C}$ ) and decrease their mean $\mathrm{EC}_{50}$ value to $2.70 \mathrm{mM}(95 \% \mathrm{CI}, 2.60-2.80 \mathrm{mM})$, a value that was indistinguishable from the $\mathrm{EC}_{50}$ of untreated WT cells (Figure 2, C and D). Thus, cinacalcet normalized the signaling responses of Gly195 mutant cells. 
A

$$
\begin{array}{ccccc}
578 & 581 & 584 & 587 & 590 \\
\text { ' } & \text { ' } & \text { ' } & \text { I' } & \text { ' } \\
\text { С С T T TC } & \text { G A } & \text { C C T G } & \text { G A G }
\end{array}
$$

Gna11 ${ }^{++}$

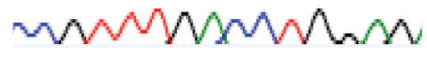

C CTT TC G N C T T GAG

Gna11+195G

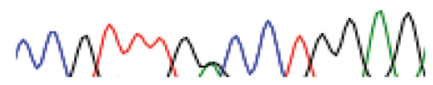

CCTT TC G G CC T G GA G

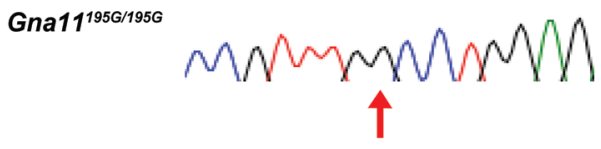

C

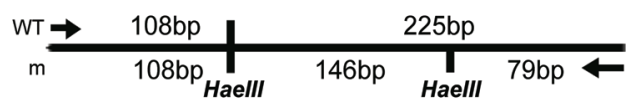

B

Codon $193 \quad 194 \quad 195 \quad 196 \quad 197$

WT Asp

Amino acid Pro Phe Leu Glu

Mutant (m) Gly

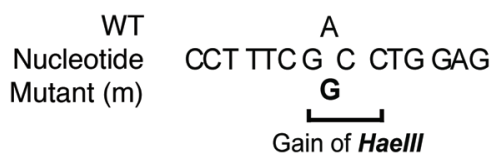

D

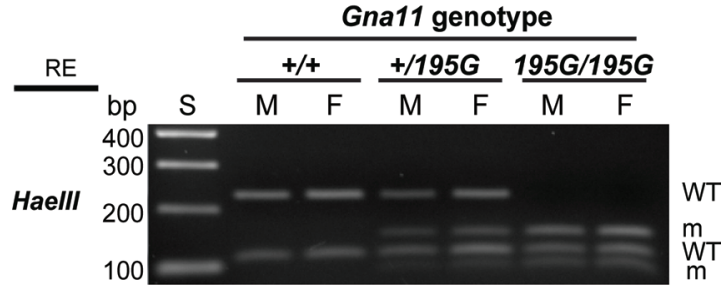

Figure 3. DNA sequence and restriction endonuclease analysis of the Asp195Gly $G \alpha_{11}$ mutation. (A) DNA sequence analysis showing an A-to- $C$ transition at c.584 (red arrow) within exon 3 of Gna11 (numbering begins from ATC). The DNA sequence chromatograms show that WT (Gna11+/) mice are homozygous A/A,

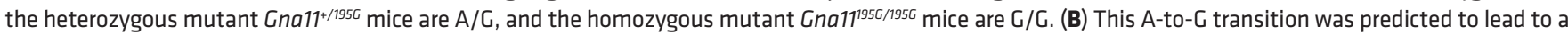
missense substitution of Asp, encoded by GAC, to Gly, encoded by GCC, at codon 195 and resulted in the gain of a Haelll restriction endonuclease (RE) site (GG/ CC). (C) Restriction maps showing that Haelll digest would result in 2 products of 108 bp and 225 bp for the WT, and 3 products of 108 bp, 146 bp, and 79 bp for the mutant (m). (D) RE digest of Gna11 exon 3 PCR products demonstrating that WT (Gna11+/+) mice are homozygous for the WT alleles, mutant Gna11+/195C mice are heterozygous and have WT and $\mathrm{m}$ alleles, and mutant Gna11956/1955 mice are homozygous for $\mathrm{m}$ alleles. M, male; F, female; S, size marker.

In vivo functional analysis in mice harboring the germline Gna11 Asp195Gly mutation. To investigate the in vivo effects of the Asp195Gly $\mathrm{G} \alpha_{11}$ mutation on $\mathrm{Ca}^{2+}{ }_{0}$ homeostasis, ENU mutagenesis-derived mice harboring this mutation were established on the $\mathrm{C} 3 \mathrm{H}$ inbred genetic background (24). DNA sequence analysis confirmed the mutant mice to harbor a germline A-to- $\mathrm{G}$ transition at c.584A $>\mathrm{G}$ at codon 195 of the $G \alpha_{11}$ protein resulting in an Asp (D) to Gly (G) missense substitution (Figure 3, A and B). This mutation led to a gain of a HaeIII restriction endonuclease site (Figure 3C), which was used to confirm the presence of the mutation (Figure 3D) and to genotype the subsequent generations of mice. Heterozygous-affected $\left(G n a 11^{+/ 195 G}\right)$ mice were healthy and fertile, and an analysis of offspring bred from crosses of Gna11 ${ }^{+/ 195 G}$ mice yielded homozygous-affected (Gna11 ${ }^{195 G / 195 G}$ ) mice and significant deviations from the Mendelian inheritance expected ratio of 1:2:1 for the WT $\left(\right.$ Gna11 $\left.1^{+/+}\right)$, Gna11 ${ }^{+/ 195 G}$, and Gna11 ${ }^{195 G / 195 G}$ genotypes were not observed among the weaned mice, thereby indicating that the homozygous Gna11 ${ }^{195 G / 195 G}$ mice were viable and did not have embryonic or neonatal lethality (Table 1).

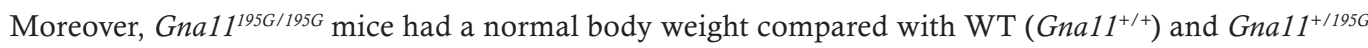
littermates (Table 2). Thus, Gna1 $1^{195 G / 195 G}$ mice did not have evidence of growth retardation or neonatal lethality to suggest an NSHPT phenotype. However, plasma biochemical analysis revealed Gna11 $1^{+/ 195 G}$

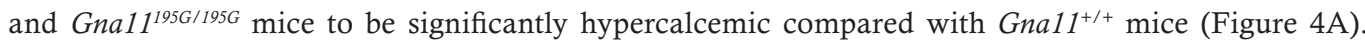
Moreover, Gna11 195G/195G mice had significantly reduced plasma phosphate concentrations and raised

Table 1. Proportion of offspring bred from crosses of Gna11+/195C $\times \mathrm{Gna11}^{+/ 195 \mathrm{C}}$ mice

\begin{tabular}{ccc}
\hline Genotype & Expected number of offspring $(\boldsymbol{n}=\mathbf{3 5 8}$ born) & Observed number of offspring $(\boldsymbol{n}=\mathbf{2 3 4}$ weaned) \\
$+/+$ & $89(25 \%)$ & $56(24 \%)$ \\
$+/ 195 G$ & $180(50 \%)$ & $127(54 \%)$ \\
$195 G / 195 G$ & $89(25 \%)$ & $51(22 \%)$
\end{tabular}

The Mendelian inheritance expected ratio from heterozygous crosses is 1:2:1, and $\chi^{2}$ analysis shows no significant differences in the expected vs. observed ratios of offspring genotypes at weaning (i.e., 19-21 days of age) $\left(x^{2}=1.0\right.$, degrees of freedom $=2$ ). 


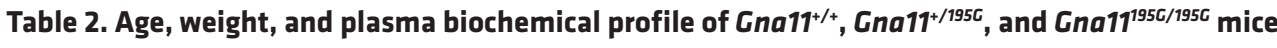

\begin{tabular}{|c|c|c|c|c|c|c|}
\hline \multirow[t]{2}{*}{ Parameter } & \multicolumn{3}{|c|}{ Male } & \multicolumn{3}{|c|}{ Female } \\
\hline & Gna11+/+ & Gna11+/195G & Gna11195L/195G & Gna11+/+ & Gna11+/195L & Gna11956/1956 \\
\hline Age (weeks) & $13.9 \pm 0.1(n=12)$ & $14.0 \pm 0.1(n=13)$ & $13.9 \pm 0.1(n=14)$ & $13.8 \pm 0.1(n=10)$ & $13.8 \pm 0.1(n=15)$ & $13.6 \pm 0.1(n=13)$ \\
\hline Sodium (mmol/l) & $149 \pm 0.7(n=12)$ & $151 \pm 0.5(n=13)$ & $150 \pm 0.6(n=13)$ & $149 \pm 0.6(n=10)$ & $148 \pm 0.7(n=15)$ & $147 \pm 0.6(n=13)$ \\
\hline Potassium (mmol/l) & $5.4 \pm 0.1(n=12)$ & $5.2 \pm 0.1(n=13)$ & $5.3 \pm 0.1(n=13)$ & $5.0 \pm 0.1(n=10)$ & $4.9 \pm 0.1(n=15)$ & $4.9 \pm 0.2(n=13)$ \\
\hline Urea (mmol/l) & $10.7 \pm 0.6(n=12)$ & $9.8 \pm 0.3(n=13)$ & $10.1 \pm 0.4(n=13)$ & $8.6 \pm 0.6(n=10)$ & $8.8 \pm 0.2(n=15)$ & $9.0 \pm 0.3(n=12)$ \\
\hline $\begin{array}{l}\text { Adj-calcium } \\
(\mathrm{mmol} / \mathrm{l})^{A}\end{array}$ & $2.36 \pm 0.02(n=12)$ & $2.41 \pm 0.02(n=12)$ & $2.48 \pm 0.02(n=13)^{\mathrm{D}}$ & $2.39 \pm 0.02(n=10)$ & $2.45 \pm 0.01(n=15)$ & $2.58 \pm 0.02(n=13)^{D, E}$ \\
\hline Albumin (g/l) & $25.2 \pm 0.3(n=12)$ & $24.8 \pm 0.3(n=12)$ & $25.0 \pm 0.2(n=13)$ & $26.2 \pm 0.4(n=10)$ & $26.5 \pm 0.4(n=15)$ & $26.9 \pm 0.4(n=13)$ \\
\hline $\begin{array}{l}\text { Magnesium } \\
(\mathrm{mmol} / \mathrm{l})\end{array}$ & $0.80 \pm 0.02(n=12)$ & $0.76 \pm 0.02(n=13)$ & $0.76 \pm 0.02(n=13)$ & $0.81 \pm 0.02(n=10)$ & $0.83 \pm 0.02(n=15)$ & $0.85 \pm 0.02(n=13)$ \\
\hline FGF-23 (ng/I) & $149 \pm 7(n=12)$ & $170 \pm 5(n=11)$ & $173 \pm 8(n=12)$ & $150 \pm 4(n=10)$ & $146 \pm 7(n=14)$ & $160 \pm 8(n=13)$ \\
\hline \multicolumn{7}{|c|}{$\begin{array}{l}\text { APlasma calcium concentrations were adjusted according to the mean plasma albumin concentration of respective male and female WT mice. Adj-calcium, } \\
\text { albumin-adjusted calcium; ALP, alkaline phosphatase activity; PTH, parathyroid hormone; } 1,25 D, 1,25 \text { dihydroxyvitamin } D ; \text { FGF- } 23 \text {, fibroblast growth } \\
\text { factor- } 23 \text {. All values are expressed as mean } \pm \text { SEM. A Kruskal-Wallis test followed by Dunn's test for nonparametric pairwise multiple comparisons were } \\
\text { used to compare mutant mice with WT mice, and a Mann-Whitney } U \text { test was used to compare respective male and female mice. }{ }^{B} P<0.05 \text {, }{ }^{C} P<0.01,{ }^{D} P< \\
0.001 \text { compared with respective Gna11+/+ mice. }{ }^{E} P<0.001 \text { compared with respective male mice. }\end{array}$} \\
\hline
\end{tabular}

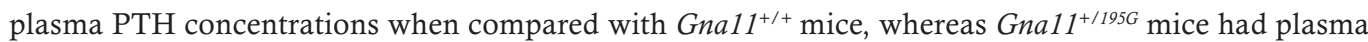

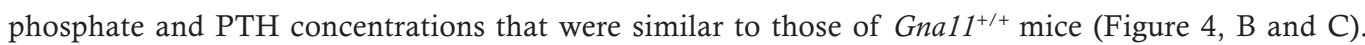
Furthermore, the fractional excretion of calcium was not altered in Gna11 ${ }^{+/ 195 G}$ or Gna11 ${ }^{195 G / 195 G}$ mice compared with Gna11+/+ mice (Figure 4D and Table 3). However, there were sex differences in these calcitropic phenotypes, as follows. Female Gna11 ${ }^{195 G / 195 G}$ mice were significantly more hypercalcemic than male Gna11 $1^{195 G / 195 G}$ mice and female Gna11 ${ }^{+/ 195 G}$ mice (Table 2 and Supplemental Figure 2). In addition, female Gna11 ${ }^{195 G / 195 G}$ mice, but not the Gna11 mutant males, had significant hypophosphatemia, with a significant reduction in the tubular maximum reabsorption of phosphate (Table 3 ) and a raised

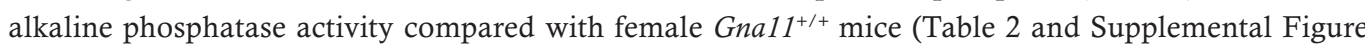
2). Significant differences were not observed in plasma electrolytes, urea and creatinine concentrations, or 1,25-dihydroxyvitamin D or fibroblast growth factor-23 (FGF-23) concentrations in male or female

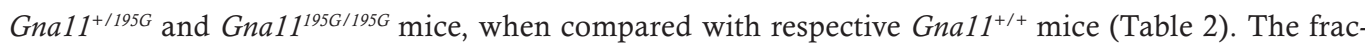
tional excretions of sodium and potassium were also not different between male and female mutant mice and respective Gna11 ${ }^{+/+}$mice (Table 3). Finally, whole body dual-energy X-ray absorptiometry (DXA) did not reveal significant differences in the bone mineral content or bone mineral density (BMD) between male and female mutant mice and respective $G n a 11^{+/+}$mice (Table 4).

To determine whether the hypercalcemia of Gna11 ${ }^{+/ 195 G}$ and Gna11 195G/195G mice may be improved by in vivo calcimimetic treatment, we administered cinacalcet to WT and mutant mice. A pilot dose-ranging study in WT mice showed that a single oral gavage $30 \mathrm{mg} / \mathrm{kg}$ dose of cinacalcet significantly lowered plasma PTH concentrations, when compared with vehicle-treated mice (Supplemental Figure 3). This dose $(30 \mathrm{mg} / \mathrm{kg})$ of cinacalcet was therefore administered by oral gavage to $\mathrm{Gna11^{+/+ }}$, Gna11 ${ }^{+/ 195 G}$, and Gna11 ${ }^{195 G / 195 G}$ mice, and plasma samples were then taken at 0, 1, 2, 4, 6, and 24 hours after dose for the measurement of PTH, calcium, phosphate, urea, creatinine, and albumin concentrations. Administration of cinacalcet significantly decreased plasma PTH concentrations in $G n a 11^{+/+}, G n a 11^{+/ 195 G}$, and Gna11 $1^{195 G / 195 G}$ mice by $\geq 60 \%$ at 1 hour after dose, with values returning to baseline by 4-6 hours after dose (Figure 5, A-C), and it significantly reduced plasma albumin-adjusted calcium concentrations in Gnal1 $1^{+/+}$, Gna11 $1^{+/ 195 G}$, and Gna11 $1^{195 G / 195 G}$ mice between 2-6 hours after dose, with values returning to 
A
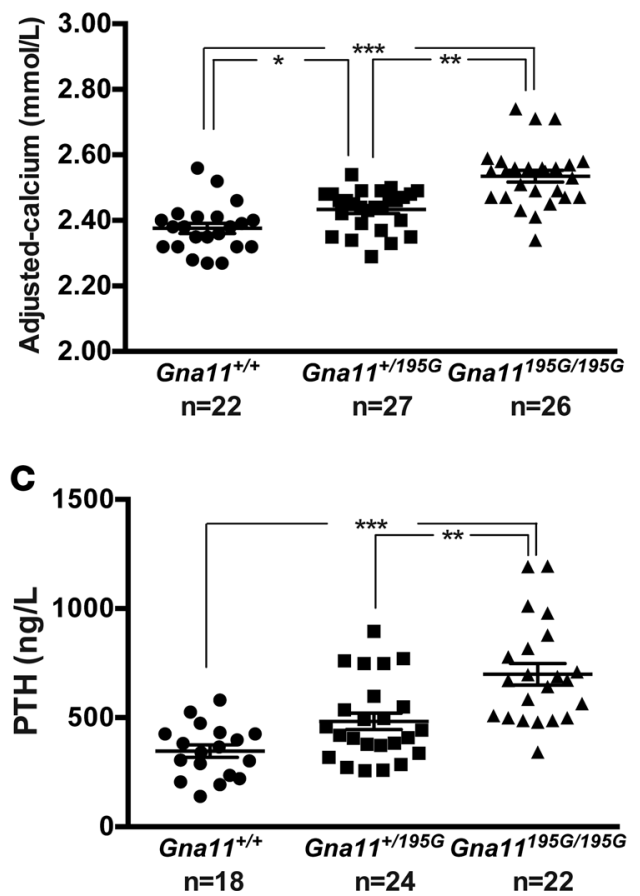

B

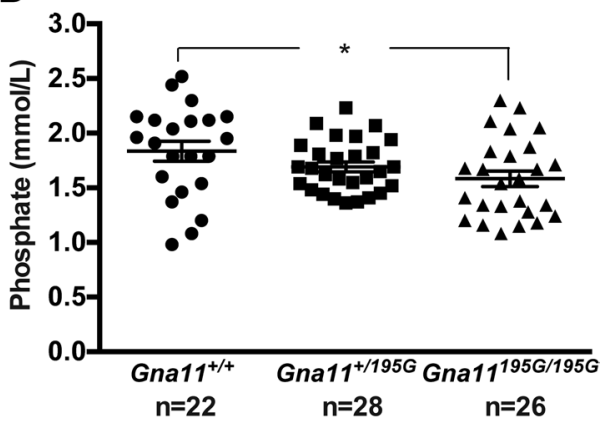

D

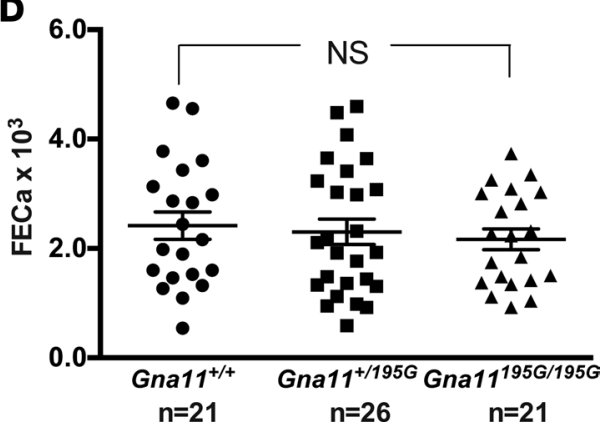

Figure 4. Calcitropic phenotype of $\mathrm{Gna11}^{+/+}, \mathrm{Gna11}^{+/ 195 C}$, and $\mathrm{Gna11}{ }^{1956 / 195 C}$ mice. (A) Plasma albumin-adjusted calcium concentrations, (B) plasma phosphate concentrations, (C) plasma parathyroid hormone (PTH) concentrations, and (D) fractional excretion of calcium (FECa) of $\mathrm{Cna11}^{+/+}$(circles),

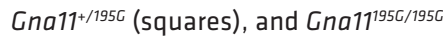
(triangles) mice, respectively. Combined data from males and females are shown. Mean \pm SEM values for the respective groups are indicated by the solid bars. A Kruskal-Wallis test followed by Dunn's test for nonparametric pairwise multiple comparisons were used for analysis of $\mathbf{A}-\mathbf{D}$. ${ }^{*} P<$ $0.05,{ }^{* *} P<0.01,{ }^{* *} P<0.001$.

baseline by 24 hours after dose (Figure 5, D-F). Cinacalcet treatment also resulted in a transient rise in

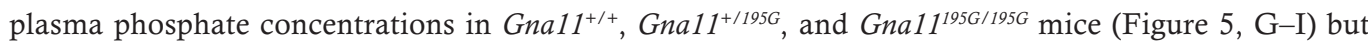
was not associated with any increases in plasma concentrations of urea or creatinine (Supplemental Figure 4). Thus, these studies demonstrated that cinacalcet is effective in vivo and can reduce raised plasma calcium and PTH concentrations observed in Gna11 mutant mice with a loss-of-function G $\alpha_{11}$ mutation, which is representative of $\mathrm{FHH} 2$.

\section{Discussion}

We have established a mouse model for $\mathrm{FHH} 2$, and this will enable the calcitropic roles of $\mathrm{G} \alpha_{11}$ to be further evaluated and also facilitate further pathophysiological studies that are difficult to pursue in the few reported patients with this condition. Our results revealed that heterozygous-affected (Gna11 ${ }^{+/ 195 G}$ ) mice had a similar plasma biochemical phenotype to that reported for FHH2 patients, who also harbor heterozygous loss-of-function $\mathrm{G} \alpha_{11}$ mutations (Table 5) $(3,10)$. Thus, Gna11 ${ }^{+/ 195 G}$ mice had mild hypercalcemia in association with normal plasma PTH concentrations; they also had no alterations in the plasma concentrations of phosphate and creatinine, or in alkaline phosphatase activity, which is consistent with

Table 3. Urine biochemical profile of $\mathrm{Gna11}^{+/+}$, Gna11+/195C , and Gna11956/195C mice

\begin{tabular}{|c|c|c|c|c|c|c|}
\hline \multirow[t]{2}{*}{ Parameter } & \multicolumn{3}{|c|}{ Male } & \multicolumn{3}{|c|}{ Female } \\
\hline & Gna11+/+ & Gna11+/195C & Gna1195G/195C & Gna11+/+ & Gna11+/195C & Gna1195C/195C \\
\hline $24 \mathrm{hrCa}$ & $4.9 \pm 0.4(n=9)$ & $5.9 \pm 0.5(n=13)$ & $6.4 \pm 0.7(n=13)$ & $11.7 \pm 1.3(n=10)$ & $16.3 \pm 2.4(n=15)$ & $17.0 \pm 1.7(n=12)$ \\
\hline FECa & $1.9 \pm 0.3(n=11)$ & $1.5 \pm 0.2(n=13)$ & $1.4 \pm 0.2(n=12)$ & $2.9 \pm 0.3(n=10)^{\mathrm{B}}$ & $3.1 \pm 0.3(n=13)^{\mathrm{c}}$ & $3.0 \pm 0.2(n=9)^{c}$ \\
\hline $\mathrm{FENa}$ & $5.3 \pm 0.4(n=12)$ & $4.7 \pm 0.4(n=13)$ & $5.2 \pm 0.5(n=13)$ & $6.1 \pm 0.2(n=10)$ & $6.1 \pm 0.3(n=15)$ & $6.0 \pm 0.3(n=13)$ \\
\hline FEK & $0.20 \pm 0.004(n=11)$ & $0.18 \pm 0.02(n=13)$ & $0.20 \pm 0.01(n=13)$ & $0.21 \pm 0.01(n=10)$ & $0.23 \pm 0.01(n=15)$ & $0.21 \pm 0.01(n=13)$ \\
\hline
\end{tabular}

Parameters were measured using urine samples obtained over a 24-hour period. Urinary calcium excretion values are shown as $\mu$ mol/24 hours. Calcium/ creatinine ratios ( $\mathrm{Ca} / \mathrm{Cr}$ ) are shown as mmol/mmol. Fractional excretion (FE) of Ca and Na are multiplied by 1,000. TmP/CFR, ratio of tubular maximum reabsorption of phosphate (TmP) to GFR. All values are expressed as mean \pm SEM. A Kruskal-Wallis test followed by Dunn's test for nonparametric pairwise multiple comparisons were used for all analyses. ${ }^{A} P<0.05$ compared with respective Gna11+/+ mice. ${ }^{B} P<0.05$, ${ }^{C} P<0.001$ compared with respective male mice. 


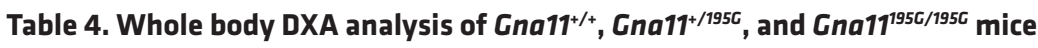

\begin{tabular}{|c|c|c|c|c|c|c|}
\hline \multirow[t]{2}{*}{ Parameter } & \multicolumn{3}{|c|}{ Male } & \multicolumn{3}{|c|}{ Female } \\
\hline & Gna11+/+ & Gna11+/195C & Gna1195G/195C & Gna11+/+ & Gna11+/195C & Cna1195L/195C \\
\hline $\mathrm{BMC}(\mathrm{g})$ & $\begin{array}{c}0.60 \pm 0.01 \\
(n=12)\end{array}$ & $\begin{array}{c}0.62 \pm 0.01 \\
(n=13)\end{array}$ & $\begin{array}{c}0.63 \pm 0.01 \\
(n=14)\end{array}$ & $\begin{array}{c}0.57 \pm 0.01 \\
(n=9)\end{array}$ & $\begin{array}{c}0.59 \pm 0.01 \\
(n=14)\end{array}$ & $\begin{array}{c}0.57 \pm 0.01 \\
(n=12)\end{array}$ \\
\hline BMC (corr) & $\begin{array}{c}0.02 \pm 0.0004 \\
(n=12)\end{array}$ & $\begin{array}{c}0.02 \pm 0.001 \\
(n=13)\end{array}$ & $\begin{array}{c}0.02 \pm 0.001 \\
(n=14)\end{array}$ & $\begin{array}{c}0.02 \pm 0.001 \\
(n=9)\end{array}$ & $\begin{array}{c}0.02 \pm 0.001 \\
(n=15)\end{array}$ & $\begin{array}{c}0.019 \pm 0.001 \\
(n=12)\end{array}$ \\
\hline $\mathrm{BMD}\left(\mathrm{g} / \mathrm{cm}^{2}\right)$ & $\begin{array}{c}0.065 \pm 0.001 \\
(n=12)\end{array}$ & $\begin{array}{c}0.065 \pm 0.001 \\
(n=13)\end{array}$ & $\begin{array}{c}0.069 \pm 0.002 \\
(n=14)\end{array}$ & $\begin{array}{c}0.067 \pm 0.001 \\
(n=9)\end{array}$ & $\begin{array}{c}0.066 \pm 0.001 \\
(n=15)\end{array}$ & $\begin{array}{c}0.067 \pm 0.003 \\
(n=12)\end{array}$ \\
\hline
\end{tabular}

DXA, dual-energy X-ray absorptiometry; BMC, bone mineral content; BMC (corr), BMC corrected for body weight; BMD, bone mineral density. All values are expressed as mean \pm SEM. A Kruskal-Wallis test followed by Dunn's test for nonparametric pairwise multiple comparisons were used for all analyses. ${ }^{A} P=0.06$ compared with respective Gna11+/+ mice.

the reported phenotype of $\mathrm{FHH} 2$ patients (Table 5) $(3,10)$. Gna11 ${ }^{+/ 195 G}$ mice additionally had normal plasma magnesium concentrations, which is consistent with one reported FHH2 proband (3) but which contrasts with the hypermagnesemia reported in a multigenerational FHH2 kindred (3). A key finding of this study is that Gna11 $1^{+/ 195 G}$ and Gna1 $1^{195 G / 195 G}$ mice had no alterations in urinary calcium excretion, and this would be consistent with studies of $\mathrm{FHH} 2$ patients, which have reported that not all $\mathrm{FHH} 2$ patients have a low fractional excretion of calcium (Table 5$)(3,10)$. The absence of a urinary calcium phenotype in Gna11 ${ }^{+/ 195 G}$ and Gna11 ${ }^{195 G / 195 G}$ mice is also consistent with the reported findings in mice and humans harboring germline gain-of-function $\mathrm{G} \alpha_{11}$ mutations that is associated with hypocalcemia and reduced plasma PTH concentrations but with mild or no alterations in urinary calcium excretion (25-27). These studies highlight a potential difference in the calcitropic phenotype of disorders caused by germline $G \alpha_{11}$ mutations and that of disorders caused by germline CaSR mutations, and they suggest that the $\mathrm{G} \alpha_{11}$ protein may not play a major role in the renal handling of calcium. Thus, it remains to be established whether hypocalciuria represents a major component of the FHH2 disorder in humans. Furthermore, DXA analysis did not reveal any alterations in the BMD values of Gna11 195G/195G mice, which also suggests that the $\mathrm{G} \alpha_{11}$ protein may not influence bone mass.

Our studies of homozygous-affected (Gna11 $1^{195 G / 195 G}$ ) mice have highlighted the importance of $\mathrm{G} \alpha_{11}$ for parathyroid gland function and PTH secretion, as Gna11 195G/195G mice had more pronounced hypercalcemia and hypophosphatemia, and significantly raised plasma PTH concentrations, consistent with primary hyperparathyroidism (28). Moreover, female Gna11 ${ }^{195 G / 195 G}$ mice also had significant elevations of plasma alkaline phosphatase activity, which is consistent with an elevated bone turnover associated with this likely primary hyperparathyroidism. However, the hypercalcemic phenotype of Gna11 195G/195G mice was, in general, milder than that observed in humans or mice harboring biallelic loss-of-function CaSR mutations, which typically lead to the life-threatening disorder of NSHPT (12, 24). A possible explanation for the milder hypercalcemic phenotype observed in the Gna11 ${ }^{195 G / 195 G}$ mice is that the loss of $\mathrm{G} \alpha_{11}$ function caused by the Asp195Gly mutation in vivo was partially compensated by the WT G $\alpha_{\alpha}$ protein, which in the parathyroid glands continues to mediate signal transduction by the CaSR. Indeed, the importance of the $\mathrm{G} \alpha_{11}$ and $\mathrm{G} \alpha_{\mathrm{q}}$ proteins for parathyroid gland function has been demonstrated by studies of mice with a parathyroid-specific ablation of both $G \alpha_{11}$ and $G \alpha_{q}$, which have been reported to develop features of NSHPT such as severe hypercalcemia, skeletal demineralization, growth retardation, and early postnatal death (7). The hypercalcemia observed in Gna11 ${ }^{195 G / 195 G}$ mice was more severe in females compared with males, and such sex differences have not previously been reported in studies of FHH patients. However, sex differences have been noted in primary hyperparathyroidism patients, with females being more commonly affected than males (29). Moreover, estrogen may play a role in the pathogenesis and severity of primary hyperparathyroidism, as highlighted by a study that showed the potential involvement of estrogen signaling in parathyroid function and disease (30); such effects may have contributed to the more severe hypercalcemia of female Gna11 ${ }^{195 G / 195 G}$ mice.

There is currently no effective treatment for $\mathrm{FHH} 2$, and we therefore evaluated the therapeutic potential of cinacalcet, which is a licensed CaSR-positive allosteric modulator (13), for this condition. 

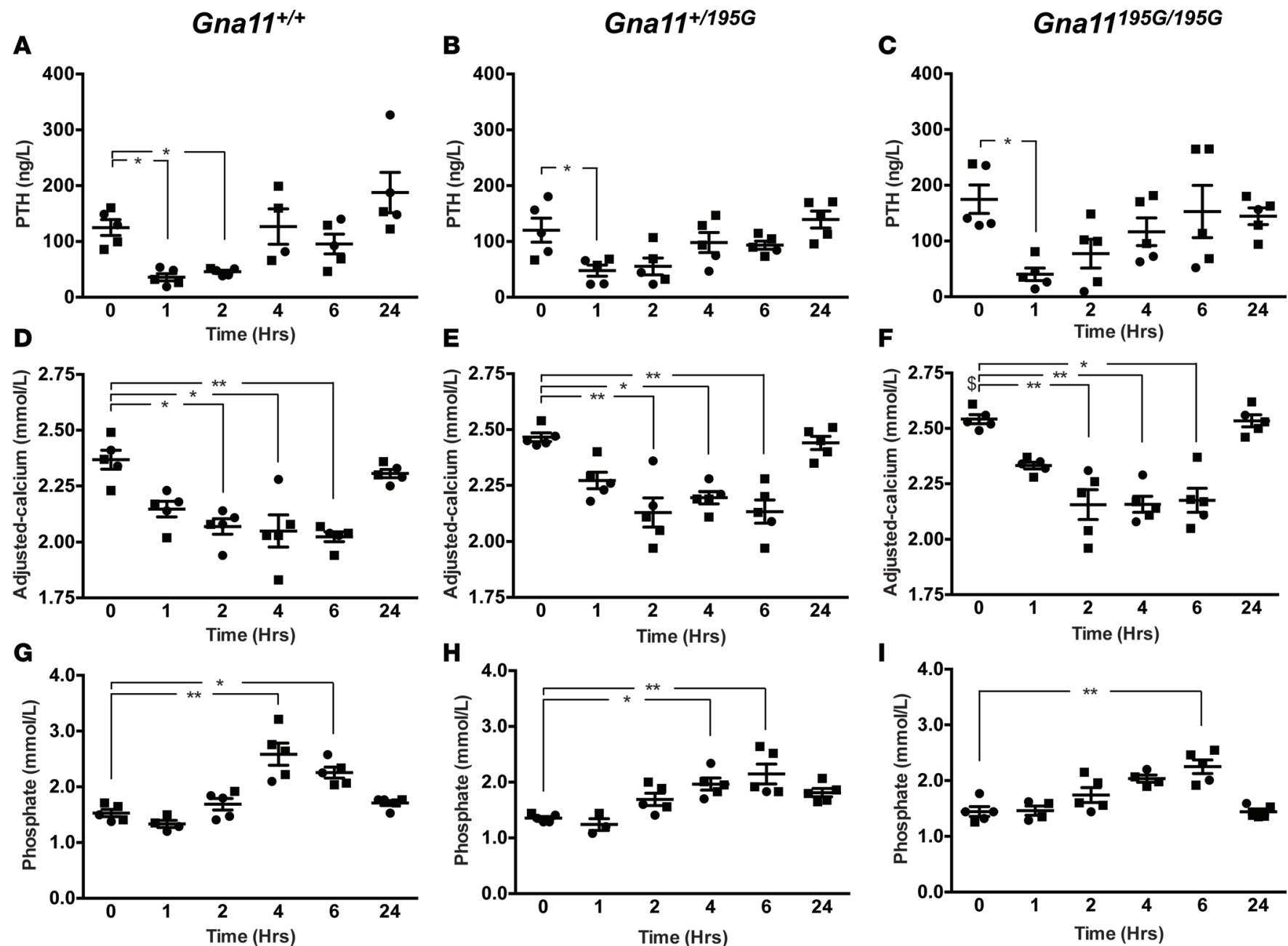

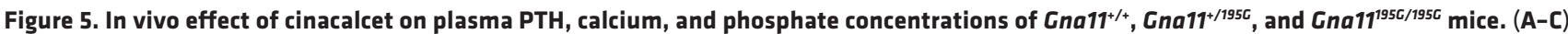
Plasma parathyroid hormone (PTH), (D-F) plasma albumin-adjusted calcium, and (G-I) plasma phosphate concentrations are shown at 0, 1, 2, 4, 6, and 24 hours following oral gavage administration of a single $30 \mathrm{mg} / \mathrm{kg}$ cinacalcet dose. Mean values for the respective groups are indicated by solid bars. $n=4-5$ mice per study time point. Squares, males; circles, females. A Kruskal-Wallis test followed by Dunn's test for nonparametric pairwise multiple comparisons were used for analysis of $\mathbf{A}-\mathbf{I} .{ }^{*} P<0.05,{ }^{* *} P<0.01$ compared with respective untreated mice. ${ }^{\$}$ Untreated Gna11956/195G mice were signifi-

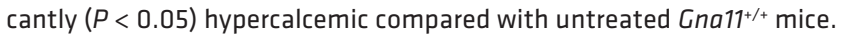

In vitro studies have previously reported that nanomolar concentrations of cinacalcet can successfully rectify the altered signaling responses of HEK-CaSR cells expressing FHH2-associated $\mathrm{G}_{11}$ mutant proteins (23). Consistent with these findings, our study showed a $10 \mathrm{nM}$ concentration of cinacalcet to normalize the $\mathrm{Ca}^{2+}{ }_{\mathrm{i}}$ responses of HEK-CaSR cells expressing the mutant Gly $195 \mathrm{G} \alpha_{11}$ protein. Moreover, oral administration of a single $30 \mathrm{mg} / \mathrm{kg}$ cinacalcet dose led to a transient suppression of PTH secretion in Gna11 $1^{+195 G}$ and Gna11 $1^{195 G / 195 G}$ mice, and this was associated with a sustained reduction in plasma calcium concentrations, which lasted for $\geq 6$ hours. This dose of cinacalcet was well tolerated in the mice and did not lead to hypocalcemia, with mean plasma calcium concentrations remaining at $>2.0 \mathrm{mmol} / 1$. However, transient hyperphosphatemia was noted in cinacalcet-treated mice, which was likely to be a consequence of suppressed PTH secretion (31). These results suggest that calcimimetics such as cinacalcet will likely be of benefit for FHH2 patients, who also harbor loss-of-function $\mathrm{G} \alpha_{11}$ mutations (23).

In summary, we have established a mouse model for FHH2 and have shown the in vivo efficacy of cinacalcet in reducing plasma calcium and PTH concentrations, thereby illustrating the potential utility of this CaSR allosteric modulator for the treatment of hypercalcemia in patients with FHH2. 
Table 5. Comparison of the phenotypes of FHH2 patients with mice harboring a loss-of-function Gna11 mutation

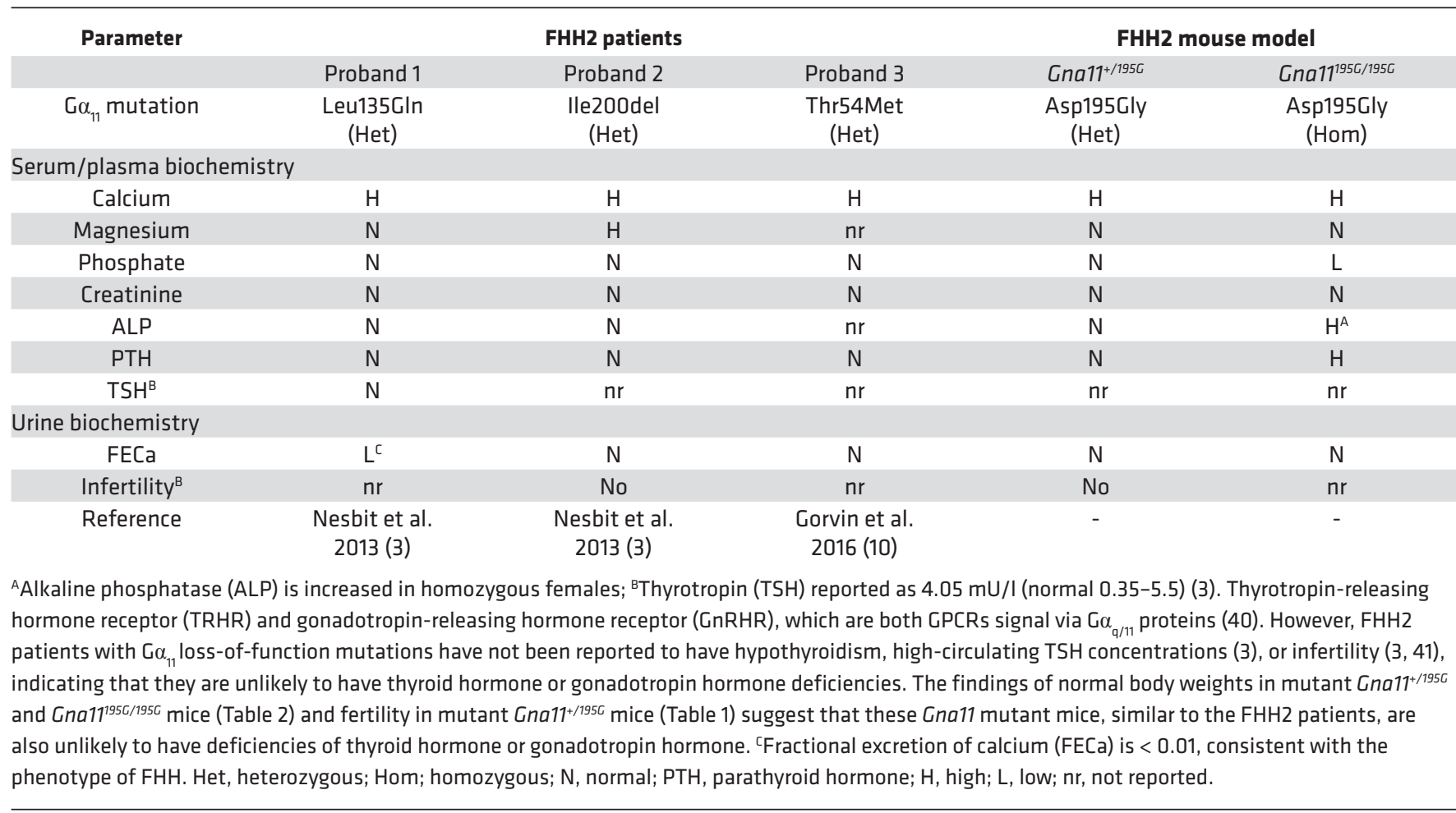

\section{Methods}

Animals. ENU-treated G0 C57BL/6J male mice (The Jackson Laboratory) were mated to C3H/HeH $(\mathrm{C} 3 \mathrm{H})$ mice (MRC Harwell) to produce G1 progeny, and tissue-DNA samples from > 10,000 G1 ENU mutagenized male mice - together with their sperm — was archived, as reported (14). These tissue-DNA samples were used to identify Gna11 variants by melt curve analysis of PCR products utilizing a Lightscanner and gene-specific primers (BioFire Diagnostics Inc.), and sperm from mice with Gna11 variants was used for IVF to generate $\mathrm{G} 2$ progeny on a $\mathrm{C} 3 \mathrm{H}$ background strain, as reported $(16,24)$. Heterozygous-affected $\left(\right.$ Gna11 $\left.1^{+/ 195 G}\right)$ mutant male and female mice were intercrossed to generate homozygous (Gna11 ${ }^{195 G / 195 G}$ ) mice, which were studied along with their $G n a 11^{+/ 195 G}$ and WT $\left(\right.$ Gna11 $\left.1^{+/+}\right)$littermates. All study mice were housed in a controlled environment at the MRC Harwell Institute in accordance with UK Home Office and MRC Welfare guidance. Mice were fed on a standard diet (Rat and Mouse number 3, Special Diet Services) that contained $1.15 \%$ calcium, $0.58 \%$ phosphate, and $4089 \mathrm{IU} / \mathrm{kg}$ of vitamin $\mathrm{D}$, and they were provided with water ad libitum $(25,32)$.

Compounds. Cinacalcet (AMG-073 HCL) was obtained from Cambridge Bioscience (catalog CAY16042) and dissolved in a $20 \%$ aqueous solution of 2-hydroxypropyl- $\beta$-cyclodextrin (MilliporeSigma, catalog H107) prior to use in in vitro and in vivo studies.

DNA sequence analysis. Genomic DNA was isolated from auricular biopsies using DNA extraction buffer (10 mM NaCl, 20 mM Tris-HCl, pH 8.0, 1 mM EDTA, 10\% SDS; MilliporeSigma) and Proteinase K solution (Thermo Fisher Scientific) (25). Genomic DNA was used with Gna11 gene-specific primers (MilliporeSigma) to perform PCR amplification, followed by dideoxynucleotide sequencing using the BigDye Terminator v3.1 Cycle Sequencing Kit and an automated detection system (ABI 3730 Automated capillary sequencer, Thermo Fisher Scientific), as reported (25). MutationTasting (http://www.mutationtaster.org/) and Polyphen-2 software was used to predict variant pathogenicity $(33,34)$. The Gna11 germline mutation was confirmed by HaeIII restriction endonuclease analysis (New England Biolabs), as previously described $(3,4)$.

Protein sequence alignment and 3-D modeling. Protein sequences of $\mathrm{G} \alpha_{11}$ orthologs and paralogs were aligned with Clustal Omega (35). The PyMOL Molecular Graphics System (Version 1.2r3pre, Schrödinger LLC) was used for structural modeling based on the complexed crystal structure of $\mathrm{G} \alpha_{\mathrm{q}}$, which has $90 \%$ 
identity with $\mathrm{G} \alpha_{11}$ at the amino acid level (Protein Data Bank, accession no. 4GNK; https://www.rcsb.org/ $\mathrm{pdb} /$ home/home.do) (18). The effect of the $\mathrm{G} \alpha_{11}$ mutations upon $\mathrm{G} \alpha_{11}$ structure was modeled using the PyMod plug-in and Modeller (36).

Cell culture and transfection. Functional studies were undertaken using a human GNA11 construct (3), as the human and mouse $\mathrm{G} \alpha_{11}$ proteins share an overall amino acid identity of $98 \%$ (25) and are $100 \%$ identical in the region surrounding the mutated site. The Gly195 mutation was introduced by site-directed mutagenesis (QuikChange Lightning, Agilent Technologies) into a pBI-CMV2-GNA11-GFP expression construct, as reported (3), and WT and mutant pBI-CMV2-GNA11-GFP constructs were transiently transfected into HEK293 cells stably expressing the full-length human CASR cDNA (HEK-CaSR), as described (3). HEK-CaSR cells were maintained in DMEM-Glutamax media (Thermo Fisher Scientific) with $10 \%$ FBS (Gibco) and $400 \mu \mathrm{g} / \mathrm{ml}$ geneticin (Thermo Fisher Scientific) at $37^{\circ} \mathrm{C}, 5 \% \mathrm{CO}_{2}(3$ ). Successful transfection was confirmed by visualizing GFP fluorescence using an Eclipse E400 fluorescence microscope with an epifluorescence filter, and images were captured using a DXM1200C digital camera and NIS Elements software (Nikon) $(3,11)$. The expression of $\mathrm{G} \alpha_{11}$, CaSR, GFP, calnexin, and GAPDH proteins was confirmed by Western blot analyses using anti-G $\alpha_{11}$ (D-6, sc-390382, Santa Cruz Biotechnologies Inc.), anti-CaSR (5C10, ADD; ab19347; Abcam), anti-GFP (B-2, sc-9996, Santa Cruz Biotechnologies Inc.), anti-calnexin (AB2301, Millipore), and anti-GAPDH (AM4300, Ambion) antibodies, respectively. The Western blots were visualized using an Immuno-Star Western C kit (Bio-Rad) on a Bio-Rad Chemidoc XRS+ system $(3,10)$.

Measurement of $\mathrm{Ca}^{2+}{ }_{i}$ responses. The $\mathrm{Ca}^{2+}{ }_{\mathrm{i}}$ responses of HEK-CaSR cells expressing WT or mutant $\mathrm{G}_{11}$ proteins were measured by Fluo- 4 calcium assays adapted from methods previously published (22). HEKCaSR cells were plated in poly-L-lysine-treated black-walled 96-well plates (Corning) and were transiently transfected with $1,000 \mu \mathrm{g} / \mathrm{ml} \mathrm{pBI}-\mathrm{CMV} 2-G N A 11-G F P$. On the following day, cells were incubated in serum-free media for 2 hours and then loaded with the Fluo- $4 \mathrm{Ca}^{2+}$-binding dye, prepared according to manufacturer's instructions (Invitrogen). Cells were loaded for 40 minutes at $37^{\circ} \mathrm{C}$. Then, either a $20 \%$ aqueous solution of 2-hydoxypropyl- $\beta$-cyclodextrin (vehicle) or $10 \mathrm{nM}$ cinacalcet was added, and cells were incubated for a further 20 minutes at $37^{\circ} \mathrm{C}(19)$. Baseline measurements were made, and increasing doses of $\mathrm{CaCl}_{2}$ were injected into each well, using the PHERAstar microplate reader (BMG Labtech) automated system. Changes in $\mathrm{Ca}^{2+}{ }_{\mathrm{i}}$ were recorded on a PHERAstar instrument (BMG Labtech) at $37^{\circ} \mathrm{C}$ with an excitation filter of $485 \mathrm{~nm}$ and an emission filter of $520 \mathrm{~nm}$. The peak mean fluorescence ratio of the transient response after each individual stimulus was measured using MARS data analysis software (BMG Labtech) and expressed as a normalized response. Nonlinear regression of concentration-response curves was performed with GraphPad Prism using the normalized response at each $\left[\mathrm{Ca}^{2+}\right]_{0}$ for each separate experiment for the determination of the $\mathrm{EC}_{50}$ values.

Metabolic cage studies and biochemical analysis. Thirteen- to 15-week-old mice were individually housed in metabolic cages (Techniplast) for 24 hours with free access to food and water. Mice were allowed to acclimatize to their environment over a 72-hour period, as described (37), prior to collection of 24-hour urine samples. Twenty-four-hour urine samples were collected in tubes containing sodium azide, and blood samples were collected from the lateral tail vein under topical local anesthesia (38) or from the retro-orbital vein into lithium heparin Microvette tubes (Sarstedt) following terminal isoflurane anesthesia, as described (25, 32). Plasma and urine were analyzed for sodium, potassium, total calcium, phosphate, magnesium, urea, creatinine, and alkaline phosphatase activity on a Beckman Coulter AU680 analyzer (25, 32). Plasma calcium was adjusted for variations in albumin concentrations using the formula: plasma calcium (mmol/1) ([plasma albumin - mean albumin ( $\mathrm{g} / \mathrm{l}$ ) of respective male and female WT mice] $\times 0.02$ ), as reported (39). Hormones were measured as follows: PTH using a 2-site ELISA specific for mouse intact PTH (Immutopics); 1,25-dihydroxyvitamin D by a 2-step process involving purification by immunoextraction and quantification by enzyme immunoassay (Immunodiagnostic Systems); and FGF-23 using a 2-site ELISA kit (Kainos Laboratories), as described $(25,39)$. The fractional excretion of sodium, potassium, and calcium were calculated using the formula $\mathrm{U}_{\mathrm{x}} / \mathrm{P}_{\mathrm{x}} \times \mathrm{P}_{\mathrm{Cr}} / \mathrm{U}_{\mathrm{Cr}}$, where $\mathrm{U}_{\mathrm{x}}$ is the urinary concentration of the filtered substance (substance $x$ ) in mmol/1, $\mathrm{P}_{\mathrm{x}}$ is the plasma concentration of substance $x$ in $\mathrm{mmol} / 1, \mathrm{U}_{\mathrm{Cr}}$ is the urinary concentration of creatinine in $\mathrm{mmol} / \mathrm{l}$, and $\mathrm{P}_{\mathrm{Cr}}$ is the plasma concentration of creatinine in mmol/1. The ratio of tubular maximum reabsorption of phosphate to GFR (TmP/GFR) was calculated using the following formula: $\mathrm{P}_{\mathrm{Pi}} \times\left(1-\left[\mathrm{U}_{\mathrm{Pi}} / \mathrm{P}_{\mathrm{Pi}} \times \mathrm{P}_{\mathrm{Cr}} / \mathrm{U}_{\mathrm{Cr}}\right]\right)$, where $\mathrm{P}_{\mathrm{Pi}}$ is the plasma concentration of phosphate and $\mathrm{U}_{\mathrm{Pi}}$ is the urine concentration of phosphate $(25,32)$. 
Skeletal imaging. Bone mineral content and density were assessed by whole body DXA scanning, which was performed on mice anesthetized by inhaled isoflurane and using a Lunar Piximus densitometer (GE Medical Systems), as reported (25). DXA images were analyzed using Piximus software, as reported (25).

Statistics. All in vitro studies involved 8 biological replicates. Statistical comparisons of the $\mathrm{Ca}^{2+}{ }_{\mathrm{i}} \mathrm{EC}_{50}$ responses were undertaken using the $F$-test, as reported (3). For the in vivo studies, a Kruskal-Wallis test was undertaken for multiple comparisons, and any significant differences identified were further assessed using the Dunn's test for nonparametric pairwise multiple comparisons (25). All analyses were performed using GraphPad Prism (GraphPad), and a value of $P<0.05$ was considered significant for all analyses.

Study approval. Animal studies were approved by the MRC Harwell Institute Ethical Review Committee and were licensed under the Animal (Scientific Procedures) Act 1986, issued by the UK Government Home Office Department (PPL30/2433 and PPL30/3271).

\section{Author Contributions}

SAH, FMH, CMG, MAN, SDMB, RDC, and RVT designed research studies; SAH, CMG, AP, MS, TAH, and SW conducted experiments; SAH, FMH, CMG, and SEP acquired and analyzed data; and SAH, FMH, CMG, and RVT wrote the manuscript.

\section{Acknowledgments}

This work was supported by the United Kingdom MRC program grants G9825289 and G1000467 (to MAN, FMH, CMG and RVT). SAH was a Wellcome Trust Clinical Training Fellow; and RVT is a Wellcome Trust Investigator and NIHR Senior Investigator. We thank R. Head for technical assistance.

Address correspondence to: Rajesh V. Thakker, Academic Endocrine Unit, Radcliffe Department of Medicine, Oxford Centre for Diabetes, Endocrinology and Metabolism (OCDEM), Churchill Hospital, Oxford OX3 7LJ, United Kingdom. Phone: 01865.857501; Email: rajesh.thakker@ndm.ox.ac.uk.

1. Hannan FM, Babinsky VN, Thakker RV. Disorders of the calcium-sensing receptor and partner proteins: insights into the molecular basis of calcium homeostasis. J Mol Endocrinol. 2016;57(3):R127-R142.

2. Hannan FM, et al. Identification of 70 calcium-sensing receptor mutations in hyper- and hypo-calcaemic patients: evidence for clustering of extracellular domain mutations at calcium-binding sites. Hum Mol Genet. 2012;21(12):2768-2778.

3. Nesbit MA, et al. Mutations affecting G-protein subunit $\alpha 11$ in hypercalcemia and hypocalcemia. $N$ Engl J Med. 2013;368(26):2476-2486.

4. Nesbit MA, et al. Mutations in AP2S1 cause familial hypocalciuric hypercalcemia type 3. Nat Genet. 2013;45(1):93-97.

5. Hofer AM, Brown EM. Extracellular calcium sensing and signaling. Nat Rev Mol Cell Biol. 2003;4(7):530-538

6. Conigrave AD, Ward DT. Calcium-sensing receptor (CaSR): pharmacological properties and signaling pathways. Best Pract Res Clin Endocrinol Metab. 2013;27(3):315-331.

7. Wettschureck N, Lee E, Libutti SK, Offermanns S, Robey PG, Spiegel AM. Parathyroid-specific double knockout of Gq and G11 alpha-subunits leads to a phenotype resembling germline knockout of the extracellular Ca2+-sensing receptor. Mol Endocrinol. 2007;21(1):274-280.

8. Darè E, Kifor O, Brown EM, Weber G. Characterization of the phosphatidylinositol-specific phospholipase C isozymes present in the bovine parathyroid and in human kidney HEK293 cells stably transfected with the human parathyroid Ca2+-sensing receptor. J Mol Endocrinol. 1998;21(1):7-17.

9. Corbetta S, Lania A, Filopanti M, Vicentini L, Ballaré E, Spada A. Mitogen-activated protein kinase cascade in human normal and tumoral parathyroid cells. J Clin Endocrinol Metab. 2002;87(5):2201-2205.

10. Gorvin CM, et al. A G-protein Subunit- $\alpha 11$ Loss-of-Function Mutation, Thr54Met, Causes Familial Hypocalciuric Hypercalcemia Type 2 (FHH2). J Bone Miner Res. 2016;31(6):1200-1206.

11. Hannan FM, et al. Adaptor protein-2 sigma subunit mutations causing familial hypocalciuric hypercalcaemia type 3 (FHH3) demonstrate genotype-phenotype correlations, codon bias and dominant-negative effects. Hum Mol Genet. 2015;24(18):5079-5092.

12. Ho C, et al. A mouse model of human familial hypocalciuric hypercalcemia and neonatal severe hyperparathyroidism. Nat Genet. 1995;11(4):389-394.

13. Nemeth EF, Goodman WG. Calcimimetic and Calcilytic Drugs: Feats, Flops, and Futures. Calcif Tissue Int. 2016;98(4):341-358

14. Acevedo-Arozena A, Wells S, Potter P, Kelly M, Cox RD, Brown SD. ENU mutagenesis, a way forward to understand gene function. Annu Rev Genomics Hum Genet. 2008;9:49-69.

15. Piret SE, Thakker RV. Mouse models for inherited endocrine and metabolic disorders. J Endocrinol. 2011;211(3):211-230.

16. Gorvin CM, et al. N-ethyl-N-nitrosourea-Induced Adaptor Protein 2 Sigma Subunit 1 (Ap2s1) Mutations Establish Ap2s1 Loss-of-Function Mice. JBMR Plus. 2017;1(1):3-15.

17. Oldham WM, Hamm HE. Heterotrimeric G protein activation by G-protein-coupled receptors. Nat Rev Mol Cell Biol. 2008;9(1):60-71.

18. Lyon AM, Dutta S, Boguth CA, Skiniotis G, Tesmer JJ. Full-length G $\alpha(q)$-phospholipase C- $\beta 3$ structure reveals interfaces of the C-terminal coiled-coil domain. Nat Struct Mol Biol. 2013;20(3):355-362. 
19. Tesmer VM, Kawano T, Shankaranarayanan A, Kozasa T, Tesmer JJ. Snapshot of activated G proteins at the membrane: the Galphaq-GRK2-Gbetagamma complex. Science. 2005;310(5754):1686-1690.

20. Waldo GL, et al. Kinetic scaffolding mediated by a phospholipase C-beta and Gq signaling complex. Science. 2010;330(6006):974-980.

21. Flock T, Hauser AS, Lund N, Gloriam DE, Balaji S, Babu MM. Selectivity determinants of GPCR-G-protein binding. Nature. 2017;545(7654):317-322.

22. Leach $\mathrm{K}$, et al. Towards a structural understanding of allosteric drugs at the human calcium-sensing receptor. Cell Res. 2016;26(5):574-592.

23. Babinsky VN, et al. Allosteric Modulation of the Calcium-sensing Receptor Rectifies Signaling Abnormalities Associated with G-protein $\alpha$-11 Mutations Causing Hypercalcemic and Hypocalcemic Disorders. J Biol Chem. 2016;291(20):10876-10885.

24. Loh NY, et al. Autosomal dominant hypercalciuria in a mouse model due to a mutation of the epithelial calcium channel, TRPV5. PLoS ONE. 2013;8(1):e55412.

25. Gorvin CM, et al. G $\alpha 11$ mutation in mice causes hypocalcemia rectifiable by calcilytic therapy. JCI Insight. $2017 ; 2$ (3):e91103.

26. Li D, et al. Autosomal dominant hypoparathyroidism caused by germline mutation in GNA11: phenotypic and molecular characterization. J Clin Endocrinol Metab. 2014;99(9):E1774-E1783.

27. Roszko KL, et al. Knockin mouse with mutant $\mathrm{G} \alpha 11$ mimics human inherited hypocalcemia and is rescued by pharmacologic inhibitors. JCI Insight. 2017;2(3):e91079.

28. Fraser WD. Hyperparathyroidism. Lancet. 2009;374(9684):145-158.

29. Adami S, Marcocci C, Gatti D. Epidemiology of primary hyperparathyroidism in Europe. J Bone Miner Res. 2002;17 Suppl 2:N18-N23.

30. Haglund F, et al. Evidence of a functional estrogen receptor in parathyroid adenomas. J Clin Endocrinol Metab. 2012;97(12):4631-4639

31. Howles SA, et al. Cinacalcet for Symptomatic Hypercalcemia Caused by AP2S1 Mutations. N Engl J Med. 2016;374(14):1396-1398.

32. Hannan FM, et al. The Calcilytic Agent NPS 2143 Rectifies Hypocalcemia in a Mouse Model With an Activating Calcium-Sensing Receptor (CaSR) Mutation: Relevance to Autosomal Dominant Hypocalcemia Type 1 (ADH1). Endocrinology. 2015;156(9):3114-3121.

33. Adzhubei IA, et al. A method and server for predicting damaging missense mutations. Nat Methods. 2010;7(4):248-249.

34. Schwarz JM, Cooper DN, Schuelke M, Seelow D. MutationTaster2: mutation prediction for the deep-sequencing age. Nat Methods. 2014;11(4):361-362.

35. Sievers F, et al. Fast, scalable generation of high-quality protein multiple sequence alignments using Clustal Omega. Mol Syst Biol. 2011;7:539.

36. Bramucci E, Paiardini A, Bossa F, Pascarella S. PyMod: sequence similarity searches, multiple sequence-structure alignments, and homology modeling within PyMOL. BMC Bioinformatics. 2012;13 Suppl 4:S2

37. Stechman MJ, et al. Establishing normal plasma and 24-hour urinary biochemistry ranges in C3H, BALB/c and C57BL/6J mice following acclimatization in metabolic cages. Lab Anim. 2010;44(3):218-225.

38. Bentley L, et al. An N-ethyl-N-nitrosourea induced corticotropin-releasing hormone promoter mutation provides a mouse model for endogenous glucocorticoid excess. Endocrinology. 2014;155(3):908-922.

39. Esapa CT, et al. N-ethyl-N-Nitrosourea (ENU) induced mutations within the klotho gene lead to ectopic calcification and reduced lifespan in mouse models. PLoS ONE. 2015;10(4):e0122650.

40. Hsieh KP, Martin TF. Thyrotropin-releasing hormone and gonadotropin-releasing hormone receptors activate phospholipase C by coupling to the guanosine triphosphate-binding proteins Gq and G11. Mol Endocrinol. 1992;6(10):1673-1681.

41. Heath H, Leppert MF, Lifton RP, Penniston JT. Genetic linkage analysis in familial benign hypercalcemia using a candidate gene strategy. I. Studies in four families. J Clin Endocrinol Metab. 1992;75(3):846-851 